\title{
Association between maternal socio-demographic factors and low birth weight newborn in a rural area of Bihar, India
}

\author{
Kashif Shahnawaz ${ }^{1}$, Sanjay Kumar Choudhary ${ }^{2}$, Gautam Sarker ${ }^{3}$, Palash Das $^{4}$, Ranabir Pal $^{5}$, Laxman Kumar ${ }^{6}$ \\ ${ }^{1,3}$ Assistant Professor; Department of Community Medicine, M.G.M Medical College \& LSK Hospital, Kishanganj, Bihar. ${ }^{2}$ Senior \\ Resident, Department of Community Medicine, I.G.I.M.S, Patna, Bihar. ${ }^{4}$ Associate Professor, Department of Community \\ Medicine, Midnapore Medical College, Paschim Medinipur, West Bengal. ${ }^{5}$ Additional Professor, Department of Community \\ Medicine and Family Medicine, All India Institute of Medical Sciences, Jodhpur, Rajasthan. ${ }^{6}$ Assistant Professor, Department of \\ Community Medicine, M.I.M.S, Barabanki, Lukhnow, U.P, India.
}

\begin{abstract}
Low birth weight (LBW) is an important cause of perinatal, neonatal and post-natal morbidity and mortality. In developing countries, LBW of newborns is mainly due to the poor socio-economic and environmental conditions of the mother. The aim of the study was to identify and quantify the effects of age, religion, socio-economic status and occupation of mothers, in order to examine which factors were primarily responsible for LBW of babies. In this study, all singleton newborn having a weight of $<2.5 \mathrm{~kg}$ was included as a case and a weight of $\geq 2.5 \mathrm{~kg}$ was included as a control. The relation of birth-weight to few maternal factors such as age, socio-economic status, religion and occupation were studied. A total of 120 cases and 240 controls were selected. After selection of each case as defined, the next available two newborns that had fulfilled the criteria for controls given above were selected and included in the control group. This ensured a case:control ratio of 1:2. Our Study showed that the greatest number of mothers having LBW newborns were in the age group of 21 to 25 years $(50 \%$ and $45.1 \%$ in both the cases and control groups respectively), belonged to socio-economic group $\mathrm{V}(42.5 \%$ and $40 \%$ in both groups respectively) and were Hindus (96.7\% and $89.6 \%$ in both groups respectively). It was found that $70 \%$ of LBW babies were born to mothers who belonged to the labor class by occupation. This study concluded with the findings that maternal factors like age, socio-economic status, religion and occupation of the mothers were related to LBW of the newborns. Avoiding teenage pregnancies, improving the socio-economic status (SES) of people and providing better working
\end{abstract}

Keywords: Low-birth weight, Maternal factors, Socio-economic status, Rural areas, India.

\section{Introduction}

Birth weight is the single most important criterion for determining neonatal and infant mortality and morbidity. ${ }^{1}$ Many of the newborns die during their first year of life, because of low birth weight (LBW) as they become the victims of protein-energy malnutrition (PEM) and infections. ${ }^{1,2}$ The World Health Organization (WHO) has defined the term low birth weight as a birth weight of less than $2500 \mathrm{gms}$, irrespective of the duration of the gestational period. ${ }^{1}$

Low birth weight (LBW) is a sensitive indicator of the socio-economic conditions and indirectly measures the health of the mother and the child. ${ }^{2}$ The epidemiological observation depicts that infants weighing lesser than $2500 \mathrm{gms}$ are approximately 20 times more likely to die than heavier babies, closely associated with the fetal and neonatal mortality and morbidity. ${ }^{1}$ Compromised growth and cognitive development with an increased risk of cardiovascular and metabolic disorders in adult life have also been reported. ${ }^{2}$

LBW is considered as the single most important predictor of infant mortality, especially of deaths within the first month of life. ${ }^{3}$ It is among the major public health

\section{Practice Points}

- Low birth weight (LBW) is an important cause of perinatal, neonatal and post-natal morbidity and mortality.

- In developing countries, LBW of newborns is mainly due to poor socio-economic and environmental conditions of the mother.

- In the present study, the incidence of LBW newborns was found to be high among young mothers and mothers from low socio-economic group.

- Occupation was found to be significantly associated with LBW of the newborns; maximum number of LBW newborns belonged to the mothers who were laborer by occupation and they had 7.14 times higher chances of getting LBW newborns as compared to service mothers.

- Avoiding teenage pregnancies, improving SES of people and providing better working environment are essential measures for reducing the prevalence of LBW babies.

Correspondence: Dr Kashif Shahnawaz, Assistant Professor, Department of Community Medicine, M.G.M Medical College \& LSK Hospital, Kishanganj, Bihar, India. Email: kashif.shahnawaz98@gmail.com. 
problem in the world, especially in the developing countries, like India. As per the WHO estimates, globally about 25 million LBW babies are born each year, nearly $95 \%$ of them in the developing countries. ${ }^{4}$ According to the UNICEF estimate, almost every third newborn (30\%) in India is LBW. ${ }^{1}$ The NFHS-3 reported the proportion of LBW babies about $23 \%$ for rural and $19 \%$ for urban population. ${ }^{5}$ As per NFHS-3 data, the infant mortality rate is $49 / 1000$ live birth for an average or large size baby, but it is 62/1000 live birth for a smaller than average baby and 129/1000 live birth for a very small baby. ${ }^{5}$

There are numerous factors contributing to LBW, both maternal and fetal. ${ }^{1,2}$ The maternal risk-factors are biologically and socially interrelated, most are however modifiable. Krammer has identified 43 potential factors for LBW. $^{6}$ Important among them are maternal malnutrition, infections , unregulated fertility, teenage pregnancy, low weight and height of the mother, poor BMI, high parity, lack of antenatal care, presence of anemia, bad obstetrical history and medical condition of the mother, smoking during pregnancy, hypertensive disorders in pregnancy, etc.

A study conducted by Nagargoje et $a l^{7}$ suggested that mother's education, occupation, socio-economic status, physical activity during pregnancy, sleep and rest duration, age at marriage, tobacco consumption, time of registration of pregnancy, number of antenatal visits, tetanus toxoid immunization, days of iron, folic acid and calcium supplements, all are found to be significantly associated with low birth weight. These factors vary from one area to another, depending upon geographic, socio-economic and cultural factors. The mortality of LBW can be reduced if the maternal risk factors are detected early and managed properly. ${ }^{1}$ Thus, it is necessary to identify factors prevailing in a particular area responsible for LBW. During the past decade, several interventional programs including reproductive and child health have been launched all over the India to improve the health status of mothers and children. ${ }^{5}$

In rural areas of Bihar, the evidence on the association between various maternal and socio-economic factors and LBW is scarce. The case control study was therefore conducted and the Objectives are to: (i) study the effects of various maternal factors like age, socioeconomic status, religion \& occupation, associated with outcome of LBW, and (ii) to study which one of the various factors had maximum impact on LBW.

\section{Materials and Methods}

Study design: Case-control study.

Study area: Primary health centre, Mahadevdighi, Kishanganj, which is attached to the Department of Community Medicine, M.G.M medical College, Kishanganj, Bihar, India.

Study period: September 2012 to August 2013.
Sampling technique: All the consecutive mothers delivering LBW child and normal weight child were included in our study. After selection of a LBW case as defined, the next available two newborns that could have fulfilled the criteria for controls were recruited in the sample to ensure a case: control ratio of $1: 2$.

Sample size: 360 women delivering single live infants in the study-setting. By selecting 120 low birth weight and age and sex matched 240 normal birth weight (NBW) children, born during the study period; whose birth weight records were available with link workers of the ward.

Case: Low birth weight children; infants with birth weight less than $2500 \mathrm{gms}$ are low birth weight, irrespective of age of gestation. ${ }^{1}$

Control: Normal Birth Weight (NBW): Infant birth weight $\geq 2500$ gms. $^{1}$

Case: Control : 1:2, age and sex matched.

Inclusion Criteria: (i) Women with completed $6^{\text {th }}$ months of pregnancy; (ii) women agreed to follow the intervention protocol during $3^{\text {rd }}$ trimester; and (iii) pregnant women supposed to be delivered at PHC.

Exclusion Criteria: (i) mothers who did not give consent; (ii) mothers who were not available for giving information; (iii) mothers having multiple births

Study method: Pregnant women were identified in this area with the help of anganwadi workers (AWW). The study was employed for pregnant women who were registered at PHC and visited regularly for antenatal checkups and finally for their delivery at PHC. All pregnant women coming to $\mathrm{PHC}$ clinic till delivery were considered as study subjects. Verbal consent was obtained from each mother recruited for this study. A personal interview was carried out with the predesigned questionnaire for collecting data. Privacy and anonymity of the individuals were maintained. Confidentiality was gained from mothers. Institutional Ethics Committee (Communication of Decision of the Institutional Ethics/Institutional Review Board - M.G.M. Medical College, Kishanganj) approval and consent were taken.

Information regarding the maternal factors like maternal age, parity, space between pregnancies and birth history like place of delivery, gestational age at delivery and type of delivery, was obtained. Also, factors like maternal education, religion, socio-economic status and her occupation was noted. Information regarding birth weight was obtained from the available birth records.

Eligibility Criteria for both the cases and controls were: to deliver a live newborn weighing less than $2500 \mathrm{gms}$. To be eligible as a control, mothers should have delivered a single newborn weighing 2500 grams or above. Mother of babies with birth weight of 2500 grams who were born consecutively after each case, 
constituted the control group. Controls were identified from birth records as the next two eligible delivery of a non-LBW baby, after a woman delivered a LBW baby. A total of 120 cases (vaginal delivery or caesarian section) and 240 controls of age 18-35 years, who delivered a live-born single baby without congenital malformation and with gestational age 37-42 weeks, were enrolled within one day of delivery. This gave a power of $80 \%$ for detecting OR $>2.1$ as significant at $5 \%$ level, if the prevalence of exposure among controls is between $20-60 \%$. All the babies were weighed within one hour after birth. The nursing staff of the Labor Room was specially trained to record birth weight of the newborns using the digital weighing scale.

Study variables: The relation of birth weight of newborns to few maternal factors, such as age, socioeconomic status, religion and occupation of mothers were studied. Although there are many variables of LBW like- maternal age, height, pre-pregnancy weight, education, occupation, socio-economic status, type of family, parity, interval between birth of the newborn baby and the previous delivery, antenatal care during current pregnancy, iron and folic acid tablets consumption and strenuous physical activity during pregnancy, history of smoking or alcoholism, etc.

Statistical analysis: All the data were entered into the SPSS package (Version 17). Association of the maternal risk factors under study was assessed by applying chi-square test, taking a level of significance of $\mathrm{P}<0.05$. To assess the strength of association the odds ratio and $95 \%$ confidence interval of odds ratio (OR) was calculated.

\section{Results}

Table 1 shows that maximum number of mothers was in the age range of 21 to 25 years in both case and control groups, i.e. $50 \%$ and $45.4 \%$ respectively, followed by age-group range of 26 to 30 years, i.e. $35.8 \%$ and $42.9 \%$ respectively.

Table 2 summarizes the effect of socio-economic status on the birth-weight of newborns. Maximum number of mothers belonged to low-socio economic group (group V), as per Modified Udai-Pareek's classification), ${ }^{8}$ both in the case and control group. Percentage of LBW newborn was more $(42.5 \%)$ in case-group than in control group $(40.0 \%)$, but this difference was not statistically significant $(p-0.961)$. It was also observed that maximum number of mothers in both the cases and control groups ( $96.7 \%$ and $89.6 \%$, respectively) belonged to Hindu religion.

Table 3 shows that $70 \%$ of LBW newborns belonged to the mothers who were labor by occupation and they had 7.14 times (OR-7.14) higher chances of getting LBW newborns as compared to service class. The difference was found to be highly significant $(\mathrm{p}<0.001)$.

Table 1: Distribution of mothers according to age

\begin{tabular}{|l|c|c|c|c|}
\hline Age group (years) & $\begin{array}{c}\text { Cases (\%) } \\
(\mathbf{n}-\mathbf{1 2 0})\end{array}$ & $\begin{array}{c}\text { Controls (\%) } \\
(\mathbf{n}-\mathbf{2 4 0})\end{array}$ & Odds ratio & $\mathbf{9 5} \% \mathbf{C I}$ \\
\hline Up to 20 & $8(6.7 \%)$ & $18(7.5 \%)$ & 0.80 & 0.33 to 1.96 \\
\hline $21-25$ & $60(50 \%)$ & $109(45.4 \%)$ & 1 & \\
\hline $26-30$ & $43(35.8 \%)$ & $103(42.9 \%)$ & 0.75 & 0.47 to 1.21 \\
\hline$>30$ & $9(7.5 \%)$ & $10(4.2 \%)$ & 1.6 & 0.62 to 4.24 \\
\hline
\end{tabular}

Chi-square $=3.11 ; \mathrm{df}=3 ; p$-value $=0.375$

Table 2: Distribution of mothers in different socio-economic groups

\begin{tabular}{|l|c|c|c|c|}
\hline Socio-Economic Group & $\begin{array}{c}\text { Cases (\%) } \\
(\mathbf{n}-\mathbf{1 2 0})\end{array}$ & $\begin{array}{c}\text { Controls (\%) } \\
(\mathbf{n}-\mathbf{2 4 0})\end{array}$ & Odds ratio & $95 \%$ CI \\
\hline Group I & $3(2.5 \%)$ & $05(2.1 \%)$ & 1 & \\
\hline Group II & $12(10 \%)$ & $27(11.25 \%)$ & 0.74 & 0.15 to 3.61 \\
\hline Group III & $24(20 \%)$ & $45(18.75 \%)$ & 0.88 & 0.19 to 4.04 \\
\hline Group IV & $30(25 \%)$ & $67(27.9 \%)$ & 0.74 & 0.16 to 3.33 \\
\hline Group V & $51(42.5 \%)$ & $96(40 \%)$ & 0.88 & 0.20 to 3.8 \\
\hline
\end{tabular}

Chi-square $=0.618 ; \mathrm{df}=4 ; p$-value $=0.961$

Table 3: Distribution of mothers according to occupation

\begin{tabular}{|l|c|c|c|c|}
\hline Occupation & $\begin{array}{c}\text { Cases (\%) } \\
(\mathbf{n}-\mathbf{1 2 0})\end{array}$ & $\begin{array}{c}\text { Controls (\%) } \\
(\mathbf{n}-\mathbf{2 4 0})\end{array}$ & Odds ratio & $95 \%$ CI \\
\hline Labor & $84(70 \%)$ & $100(41.7 \%)$ & 7.14 & 2.43 to 20.93 \\
\hline Businessman's Housewife & $14(11.7 \%)$ & $56(23.3 \%)$ & 2.12 & 0.64 to 6.98 \\
\hline Cultivator's Housewife & $18(15 \%)$ & $50(20.8 \%)$ & 3.06 & 0.95 to 9.8 \\
\hline Service Class & $04(3.3 \%)$ & $34(14.2 \%)$ & 1 & \\
\hline
\end{tabular}

Chi-square $=28.5 ; \mathrm{df}=3 ; \mathrm{p}<0.0001$ 


\section{Discussion}

Factors associated with low birth weight (LBW), often termed as 'risk factors', and their presence in an individual woman indicates an increased chance, or risk, of bearing a LBW infant. In the present case-control study from a rural area, age and socio-economic status of mother were not significantly associated with LBW. However, religion and occupation of mothers have been identified as significant risk factors for LBW babies.

Early age of marriage and early confinement is an established custom in India. Teenage girls are physically and psychologically immature for reproduction, hence pregnancy in very young women is generally considered to be a very high risk event. In addition, there are some other factors like illiteracy, inadequate prenatal care, poor socio-economic conditions etc. that affect the outcome of pregnancy in teenage girls. ${ }^{9-11}$ In our study, association of maternal age and LBW was statistically insignificant $(\mathrm{p}=0.375)$. Our findings are consistent with the studies conducted by Mavalankar et $a l{ }^{12}$ in India and Fikree et al. ${ }^{13}$ in Pakistan. Anand \& Garg ${ }^{14}$ and Srikrishna et al. ${ }^{15}$ also found no significant relationship between maternal age and low birth weight. The present study shows that the incidence of LBW newborns is high among young mothers of age group 21-25 yrs. Similar observations were also reported by Joshi et al. ${ }^{16}$ and Negi et al. ${ }^{17} \mathrm{Negi}{ }^{17}$ et $a l$. observed that a greater number of LBW babies $(36 \%)$ were born to mothers who were less than 20 yrs of age. The relationship between maternal age and LBW was not found to be statistically significant $(\mathrm{p}>0.05)$. However, other researches in this field have noted result contrary to our findings. ${ }^{18,19}$ This may be due to lesser sample size in our study population.

Studies worldwide have examined the effect of socioeconomic status indicators on birth-weight and intrauterine growth retardation (IUGR). Low socio-economic status has been shown to be one of the major risk factors for LBW and IUGR. ${ }^{12,13}$ Our study also found that the maximum number of mothers having LBW newborns belonged to the low socioeconomic group (group $\mathrm{V}$ as per Pareek's classification Rural areas ${ }^{20}$ ), both in the case and control group. But the association was not found to be statistically significant $(p=0.961)$. This finding of our study was consistent with the studies of Arreola et al. ${ }^{21}$, who also showed that birth weight is significantly lower in infants of mothers of low socioeconomic group. Maidya et $a .^{22}$ have shown that lower the per capita income greater the chances of having a LBW baby. Ahuja \& Khanna ${ }^{23}$ used the recommendation of BG Prasad to divide socio-economic groups and reported that the mean birth weight is highest for both the sexes in group I and lowest in group $\mathrm{V}$. Moreover, the mean birth weight in group $\mathrm{V}$ is 2561.7 gms; i.e. 451.1 gms (nearly $1 / 2 \mathrm{~kg}$ ) less than in group I.

In the present study, maximum number of mothers in both the case and control groups ( $96.7 \%$ and $89.6 \%$ respectively) belonged to the Hindu religion and the association of religion and LBW was found to be significant $(p=0.01)$. Some researchers from their studies have established the fact that religion has some significance on various cultural practices, which in turn may affect the birth weight. The effect of maternal genes and race on birth weight of newborns were studied by Oord and Rowe ${ }^{24}$. Joshi et al. ${ }^{16}$ in their study of risk factors associated with LBW found the association between religion and birth weight to be statistically insignificant. A recent study in Bangladesh by Khatun \& Rahman ${ }^{25}$ found that the mother's religion was insignificant in the causation of LBW. Biswas et $a l .{ }^{26}$ observed that, with a very few exceptions, more of the variables (age, religion, literacy, type of family) were found to be significantly associated with birth weight of newborns.

One of the important factors associated with the LBW of newborns is the maternal occupation around the period of conception or during the first trimester of pregnancy. Over the past quarter of a century pregnant women have increasingly remained in the workforce. ${ }^{27}$ Despite the increasing time spent by women in the workplace, there have been few studies investigating the effects of specific maternal occupations on the birth weight of newborns. ${ }^{28}$ In our study, the greatest number of LBW newborns belonged to the mothers who were laborers by occupation, and they had 7.14 times higher chances of getting LBW newborns as compared to those in the service class. The difference was found to be highly significant $(p<0.001)$. Similar observations were documented in earlier studies. ${ }^{12,13}$ However, the association between service class and housewives (cultivator's housewives and businessman's housewives taken together) were not significant, which could be due to the rural centre where the sample size of those in the service class was comparatively smaller. Farrow and associates $^{29}$ found a difference of 148 gm between the mean birth weight of infants born to women with professional occupations and those with plant and machine operative jobs. But no significant association with birth weight was observed.

\section{Conclusion}

Out of the factors studied, significant relationships were found between religion and the occupation of mothers and low birth weight of newborns. Other factors such as age and socio-economic status of the mother were not significantly associated with LBW. Thus, it is a multi-factorial phenomenon. Hence, interventional programs should be encouraged not only in health sectors but in all those sectors concerned with social development and social welfare programs.

\section{References}

1. United Nations Children's Fund and World Health Organization. Low birth weight: Country, Regional and Global estimates. New York: UNICEF, 2004

2. Walden RV, Taylor SC, Hansen NI, Poole WK, Stoll BJ, et al. Major congenital anomalies place extremely low birth weight infants at higher risk for poor growth and developmental outcomes. Pediatrics 2007;120:e1512-9.

3. Ryan CA, Ryan F, Keane E, Hegarty H. Trend analysis and socio-economic differentials in 
infant mortality in the southern health board, Ireland. Ir Med J 2000;93:204-6.

4. Park K. Park's Textbook of Preventive and Social Medicine. $18^{\text {th }}$ Edition. Jabalpur: M/S Banarsidas Bhanot, 2005.

5. International Institute for Population Sciences (IIPS) and Macro International. National Family Health Survey (NFHS-3), 2005-06: India: Volume I. Mumbai: IIPS, 2007.

6. Kramer MS. Determinant of Low birth weight: Methodological assessment and Metaanalysis. Bull WHO 1987;65(5): 663-737.

7. Nagargoje MM, Chaudhary SS, Deshmukh JS, Gupta SC, Misra SK. A case-control study of risk factors for low birth weight in Nagpur city of Maharashtra. Ind J Comm Health 2010-2011; 22(2)-23(1):4-7.

8. Jain V. Review of Preventive and Social Medicine. $6^{\text {th }}$ edition. New Delhi: Jaypee Brothers, 2014.

9. Bhaduria S. Teenage Pregnancy: A Retrospective study. J Obstet Gynecol India 1991;41:454-6.

10. Kale KM. Socio-medical correlates of teenage pregnancy. J Obstet Gynecol India 1996;46:1804.

11. Pal A, Gupta KB, Randhawa I. Adolescent pregnancy: A high risk group. J Ind Med Assoc 1997;95:127-8.

12. Mavalankar DV, Gray Ronald H, Trivedi CR: Risk factors for preterm and term low birth weight in Ahmedabad, India. Int $J$ Epidemiol 1992;21:263-72.

13. Fikree FF, Berenes HW. Risk factors for term intrauterine growth retardation. Community based study in Karachi. Bull WHO 1994;72:58187.

14. Kiran A, Garg BS. A study of factors affecting lowbirth weight. Ind J Comm Med 2000;25(2):57 -61 .

15. Srikrishna SR, Stephen C. Birth weights in a Banglore hospital: Is the city women in the phase of a nutrition transition? Health and Population Perspect Issues 2003;26(2):74-86.

16. Joshi HS, Subba SH, Dabral SB, Dwivedi S, Kumar D, Singh S. Risk factors associated with low birth weight in newborns. Ind J Comm Med 2005;30(4):142-3.
17. Negi KS, Khandpal SD, Kukreti M. Epidemiological factors associated with Low birth weight. JK science 2006;8(1):31-4

18. Chahande MS, Jadheo AR, Wadhva SK, Ughade S. Study of some epidemiological factors in teenage pregnancy. Hospital based case comparison study. Ind J Comm Med 2002;27(3):106-8

19. Banerjee B, Pandey GK, Dutt D, Sengupta B, Mondal M, Deb S. Teenage pregnancy. A socially inflicted health hazard. Ind J Comm Med 2009;34(3):227-31.

20. Pareek U, Trivedi G. Socio-economic Status Scale (Rural). Form and manual. Delhi: Manasayan, 1964

21. Arreola LPT, Casas PC, Hernandez SF, Barragan JPV, Macias ER. Socio-economic factors and LBW in Mexico. BMC Public Health 2005; 5:20.

22. Maidya RN, Gulati PV, Chablani TD. Influence of Socio-economic and environmental factors on birth weight. Indian J Med Res 1970; 58 (5) : 651-9.

23. Ahuja N, Khanna SD. Influence of maternal factors on the birth weight of full term newborn baby. J Obst Gynaecol India 1972; 8:131.

24. Van Den Oord EJCG, Rowe DC. A step in another direction looking for maternal genetic and environmental effects on racial differences in birth-weight. Demography 2001;38(4): 573-6.

25. Khatun $\mathrm{S}$, Rahman $\mathrm{M}$. socio-economic determinants of LBW in Bangladesh. A multivariate approach. Bangladesh Med Res Counc Bull 2009;34:81-6.

26. Biswas R, Dasgupta A, Sinha RN, Chaudhuri RN. An epidemiological study of low birth weight newborns in the district of Puruliya. West Bengal Ind J Public Health 2008;52:65-71.

27. Moss NI, Carver K. Pregnant women at work: Socio-demographic perspectives. Am J Ind Med 1993; 23:541-57.

28. Office of Technology Assessment. Reproductive health hazards in the workplace. Washington DC: US GPO, 1985.

29. Farrow A, Shea KM, Little RE. Birth weight of term infants and maternal occupation in a prospective cohort of pregnant women. The ALSPAC Study Team. Occup Environ Med 1998;55(1):18-23. 